\title{
Environmental Law and the Reality of the Conservation and Management of Forests in Nigeria
}

\author{
Dr Williams Adewumi Adebayo \\ Department of Business and Industrial Law, Faculty of Law, Ekiti State University, Ado-Ekiti, Nigeria.
}

\begin{abstract}
Degradation of Forest lands and resources in Nigeria by anthropogenic factors has continued unabated in Nigeria with severe implications for environmental protection and sustainable development. Forest lands serve as the habitat for wide variety of fauna and flora which provide support for lives on the earth planet. Forests in Nigeria require adequate protection to enable people benefit maximally from the gifts of nature. This paper examined the extent and effectiveness of measures for the conservation and management of forest lands and resources in Nigeria. The data for this study were obtained primarily from both international and international legal frameworks. Journal articles, text books, newspapers and the internet provide the secondary source of information. Conservation and management of forest lands and resources in Nigeria pre-date the colonial era in some of the southern states with forests. Traditional means of protection by the designation of forests as sacred proved more potent than the use of legal instruments. In effect today, conservation and management of forests are in the actual practice limited to government owned parks, thus leaving natural forests open to assault.
\end{abstract}

Keywords: Forests, conservation, deforestation, waterfowl, ecosystem etc.

DOI: $10.7176 / \mathrm{JLPG} / 96-01$

Publication date: April $30^{\text {th }} 2020$

\section{Introduction}

Forest lands and resources play invaluable role in the existence of man on the earth planet. Forest lands and resources are one of the features that make the earth planet unique among the planetary systems. Forest lands serve as the habitation for species of plants, animals and microbes. Forest ecosystem, that is, the interconnectedness of plants, animals and microbes with the environment ensure that the forests continue to serve as natural air filters as well as water factories and source of raw materials for both orthodox and traditional medicine. Nigeria is richly endowed with abundant forest lands and resources which are located across both the northern and southern parts of Nigeria respectively. There is, however, a marked difference between the forest lands in the northern part of Nigeria and the forests in the southern part. The forest lands in the northern part are located within the savannah and Sahel region with sparse timbre resources while the forest in the southern part is located within the lowland rainforest areas with array of timbre resources. Forest lands in Nigeria can be classified as forest reserves, free areas and conservation areas. The Forest Reserves are owned by the state governments and managed by the Forestry Departments in the respective States. The permission of the government is required for the exploitation of trees in the reserves. The Free Areas are forest lands that are not under the strict control or management of the government. Permission to harvest trees is also required in this area. The Conservation Areas include National Parks, Game Reserves and Wildlife Sanctuaries.

Man and animals depend on resources from lands for survival. These resources have been greatly depleted by man in the search for the basic necessities of lives viz food, clothing and shelter. Legal Instruments have been put in place by governments for the conservation and management of forest lands and resources. There are also traditional means of protecting and conserving forest lands and resources before the advent of colonial administration, one of which was the designation of some forests as sacred and by so doing entry into such forests was strictly restricted to certain people while harvesting of forest products was completely prohibited. The governments have over the years introduced fiscal measures such as the annual tree planting campaign designed to reforest the environment. The extent at which the legal instruments and policies have assisted in the conservation of forests is the goal of this paper. Part one of this paper is the introduction while part two examined the Forests and patterns of degradation in Nigeria. The factors responsible for the degradation of forest lands are examined in part three while the legal frameworks for the conservation and management of forest lands and resources are discussed in part four. The reality of the conservation and management of forest lands and resources are discussed in part five and the last part is the conclusion.

\subsection{Forests and Patterns of Degradation in Nigeria}

A Forest area is a large area of land with assorted trees, herbs, shrubs and all manner of vegetation and wildlife. The total land area of Nigeria is estimated to be 923,768 square kilometres. The two vegetation belts in Nigeria are the forests and the savannah. The forest lands in Nigeria are mainly located in the southern part of the country and it is estimated that the forests are inhabited by 4715 species of high plants; 899 species of birds, 53 amphibians 
and 273 mammals ${ }^{1}$. The savannah vegetation stretches from the northern end of the rainforests till the southern end of the Sahara desert. Savannah vegetation in Nigeria can be classified as Guinea Savannah, Sudan Savannah, Derived Savannah and the Sahel Savannah. There are eight major types of forests in Nigeria and they are?

(a) Savannah and woodland

(b) Lowland and rainforests

(c) Freshwater and swamp forests

(d) Mangrove forests

(e) Montana forests

(f) Riparian forests

(g) Plantation(agriculture)

(h) Plantation(forest)

Forest reserves are owned by the state governments and managed by the State Forestry Departments with professional and technical staff including uniform guards performing various responsibilities. The Free Areas are forested areas that are not under strict management by the forestry departments but still, permission for exploitation of trees from the areas must be obtained from the government. The Conservation Area, on the other hand is the National Parks, Games and Wildlife Sanctuaries and Nature Reserves. The forest lands currently available in Nigeria are:

(a) Akure Forest Reserves in Ondo State, South-West, Nigeria, It covers an area of 66 square kilometres.

(b) Afi Forest Reserves in Cross River State, South-South, Nigeria. It is one of the forests that house endangered varieties of animals such as Gorillas.

(c) Edumanon Forest in the Niger-Delta region, South-South, Nigeria. It occupies a land mass of 93 square kilometres and it is the habitat for Chimpanzee, Scaler monkeys, red and olive Colubus.

(d) Idanre Forest Reserves in Ondo State, Nigeria which is one of the forests in the list of the International Union for the Conservation of Natural Resources.

(e) Ngel/Nyaki Forest Reserves, Taraba State, North-East, Nigeria and it covers about 46 square kilometres. Wildlife in the forest includes Cameroon Chimpanzee, putty nosed monkeys, Cameroon olive pigeon etc.

(f) Oluwa Forest Reserves in Ondo State, South-West, Nigeria with a land mass area of 829 square kilometres.

(g) Ise-Ekiti Forest Reserves in Ekiti State, South-West, Nigeria on a land mass of 46 square kilometres. It is one of the forests threatened by over- logging and illegal clearing for Marijuana cultivation.

(h) Okomu Forest Reserves in Edo State, South-South, Nigeria with a land mass of 1081 square kilometres. It is the habitat of many endangered species of flora and fauna. It is a home of forest elephants, buffaloes, Chimpanzee, leopards, porcupine, pangolin, antelopes etc.

(i) Oba Hills Forest Reserves, Iwo, Osun State, South-West, Nigeria. It covers a land mass area of 52 square kilometres. It is a mixture of rainforest and derived savannah vegetation. It is the habitat for some wild animals like baboon, bats, colubus monkeys, lion, antelope and pangolin

(j) Okeluse Forest Reserves, Okeluse, Ondo State, South-West, Nigeria which covers a land mass area of 144 square kilometres. It is one of the protected forests in Nigeria.

The major factor propelling degradation of forest lands in Nigeria is basically economic. The need to satisfy the basic necessities of life such as food, clothing and shelter is a driving force behind the unbridled assault on the forest lands. Agriculture was the bedrock of Nigeria economy before the discovery of oil but with the discovery of oil in 1958 and its commercial production subsequently, exploration and the exploitation of crude oil aggravated the pressure on lands especially in the oil producing areas where the people have been incapacitated in the use of land as a result of environmental degradation such as oil spillages, gas flaring, wildfire and the acidification of the land. The farmers were forced to abandon their traditional farmland already polluted or rendered useless for agriculture for a new location in the forests. As the demand for land for farming is more than the available land, the forest lands become the option for invasion and while farming in the forest, the traditional farming method of clearing the bushes, uprooting of trees and setting of bushes ablaze are equally employed. The traditional methods of farming usually leave behind a gory tale for the forest lands which have been deforested to exist without tree cover. Also is the effect on wildlife that becomes endangered and are therefore constrained to migrate to other suitable locations. The natural soil components are altered because of the use of herbicides, pesticides, inorganic fertilizers and other chemicals in farming.

The forest lands in Nigeria are richly endowed with assorted economic trees. Forest lands are the source of wood for construction activities and also for export to other foreign countries. Graduate unemployment in Nigeria has turned many youths to emergency timbre contractors. Poaching of economic trees has continued unabated as some of the forests are not adequately protected. Apart from the need for planks for use in the industrial sector, planks are needed for estate development, road construction and other manufacturing activities. Apart from the

\footnotetext{
rain-forests.mongabay.com<accessed 5/6/2019>

2 . Food and Agriculture Organization. www.fao.org/3.ab578e
} 
need for planks, palm wine is a popular liquor among the local people in the villages and towns in the southern part of Nigeria. Palm wine is obtained from palm trees by either climbing the palm trees or by uprooting/cutting down of palm trees to tap for the liquor. Uprooting or cutting down of palm trees is a practice common among palm wine tappers in the South-Western part of Nigeria while in the South Eastern part, palm trees are not uprooted or cut down but rather, the palm wine tapper climbs the palm tree. Uprooting of palm trees leads to deforestation in view of the number of palm trees required to get the quantity of palm wine to meet the demands of the consumers. According to professional palm wine tappers, a minimum of ten palm trees will be needed for tapping to obtain a twenty-five (25) litres keg of palm wine daily. The implication is that in a community of about six to eight thousand population, it is usual to have at lease ten palm wine tappers which translates to one hundred palm trees. The productive life span of a palm tree after it has been uprooted is not more than six months, hence to get palm wine throughout the year, each tapper will need to uproot twenty palm trees each. The process of tapping palm trees for palm wine invariably leads to foregoing other products from palm trees such as palm oil, palm kernel, brooms etc. Apart from this, there is the environmental implication of exposing the land to direct sunlight. The environment can be protected in the face of tapping palm tree if there is a conscious effort of replanting of palm trees.

Insurgency, terrorism and the activities of bandits that have occupied the forest lands in Nigeria are other patterns in which the forest lands in Nigeria have been degraded. The methods of operations of terrorists/insurgents which include planting of land mines, digging of trenches and setting of bushes ablaze have impacted the forest lands adversely. The weapons of warfare by both the terrorists/insurgents and the military are also the source of pollution. Carbon monoxide and other organic compounds of chlorine are discharged into the forest lands from the deadly weapons and they often accumulate in parts of both terrestrial and aquatic food chains. Acidic substance from gunfire affects chemical processes and microorganisms in the soil. This in turn has severe effects on the vitality of trees, ground cover and streams. The natural reproductive processes of wildlife and plants are disrupted because of toxification of the forest lands. Both the insurgents and the military have caused large scale deforestation of the forest lands and the deliberate use of fire as weapons by both the insurgents and the military has occasioned large scale deforestation of the forest lands and the destruction of ecosystem.

\subsection{Factors Responsible for the Degradation of Forest Lands in Nigeria}

3.1 Overpopulation- Land is required by man for productive activities and for shelter. The increase in human population means an increase for the use of land which is already fixed. The implication of overpopulation is the inevitable competition for land. The forest lands in Nigeria do not enjoy adequate protection as they were in the period between the 1970's and the early eighties when there were trained Forest Guards employed to man the forests. The introduction of modern techniques for farming has encouraged large scale commercial farming. The use of tractors in ploughing and the use of herbicides, pesticides and fertilizers have enhanced farming in such a way that there is little or no dependence on human labour required in the cultivation, planting and harvesting of farm produce. The use of modern farming equipment and chemicals serves as impetus for more people that have embraced farming as occupation. As more people engaged in farming, more farmlands are required and the fact that the traditional farmlands are inadequate, prospective farmers are forced to make incursion into the forest lands. Anthropogenic assault becomes aggravated as more people enter the forest lands.

3.2 Poverty- Poverty is the major variable that has constrained the people to act contrary to the goals of conservation and management of the forest lands and resources in Nigeria and generally in the developing nations of the world. In Nigeria, the people in the rural villages and communities still depend on fire wood as source of fuel energy for cooking. These people cannot afford the use of kerosene stove, gas cooker and electric cooker because of the cost. Forest trees are cut down and used as firewood. Apart from this, small scale enterprises such as bakery, and Garri processing firm still depend on firewood as source of energy because of epileptic state of electricity in the country. Firewood and charcoals are processed from trees and as the trees are cut down; the forest lands are gradually exposed and made hostile for wildlife and ecosystems.

3.3 Corruption- Corruption is a monster which has eaten deeply into the economic fabric of Nigeria. It is a big barrier to the implementation of environmental policies and particularly the goal of the conservation and management of forest lands and resources in Nigeria. Funds voted for the management of forest lands and resources are often diverted, embezzled or mismanaged by the politician and civil servants. Illegal activities on the forest lands are aided by government officials for gratification. Trade in endangered species of flora and fauna is made possible despite the existence of laws prohibiting same because the custom units and immigration officials are always available to compromise. In some states, the number of Forest Guards is infinitesimal compared with the size of the forest lands. In some states, there are no Forest Guards. The Forest Guards in states where they are available are not provided with ammunitions and vital equipment to aid in the performance of their duty. The fact that the forest lands are without adequate security makes it imperative for the forest to become the haven for criminals.

3.4 Unemployment- Youth unemployment in the face of astronomical and annual turn-out of graduates from tertiary institutions in Nigeria is one of the factors that have continued to promote criminal tendencies among the youths. The urban cities are already congested with the daily influx of youths from the rural areas for the non- 
existing white collar job. Other youths that cannot withstand the stress in the urban cities have chosen to remain in the rural areas to fend for themselves by either engaging in illegal felling of trees or farming. The forest lands become a sanctuary for the cultivation of narcotics such as marijuana. There are some who also have opted out to engage in terrorist activities such as kidnapping, banditry, bunkering and illegal refining of petroleum products. The Federal Government introduced the amnesty programme in 2007 in which it granted pardon to repentant militants and subsequently provide for them vocational training locally and internationally. The programme has stemmed the tide of criminal activities within the forest lands and the creeks.

3.5 Climate change- Climate change is a global phenomenon but its severity depends on the activities of the people. Illegal felling of trees without any corresponding effort of replanting exposes the forest area to the direct effect of sunlight. Climate change has made parts of the forest to be replaced by savannah type vegetation. Global warming has made the habitat previously conducive to become hostile for wildlife, thus making some species to be in danger of extinction while some are forced to migrate to a more conducive environment.

3.6 Wildfire-Wildfire occurs generally during the dry season whether in the developed or the developing countries. There is, however, a difference as to the source of wildfire in the two parts of the world. Wildfire in the developing countries and particularly in Africa is caused by human activities; some deliberate while others are accidental. The deliberate action occurs in the process of either preparing the land for cultivation at the beginning of new farming season or during the process of hunting for wildlife. Bush meat is a delicacy in Nigeria and hunters enter the forest at will either in the night or during the day hunting for these animals. The bushes or forest lands are set ablaze by farmers in order to force the animals out of their location. Wildfire may occur accidentally from cigarettes or fire from cooking in the farmsteads. Pipeline vandalisation may also cause fire outbreak. Major fire disasters in Nigeria are caused by fire arising from oil spillages.

\subsection{Legal Frameworks for the Conservation and Management of Forest Lands and Resources}

Conservation and management of forest lands and resources are of global concerns in view of its potential to aid rapid social-economic development. Forests as observed by the United Nations are essential to economic development and the maintenance of all forms of life ${ }^{1}$. Forests play a vital role in maintaining the ecological processes and balance at the local, national, regional and global levels by protecting fragile ecosystems, watersheds and freshwater resources. They also serve as the rich storehouses of biodiversity and biological resources and sources of genetic materials for biotechnology products as well as photosynthesis ${ }^{2}$. The vital role of forests in national development was the primary impetus that propelled international legal frameworks relevant to the conservation and management of forests:

4.1The United Nations Forest Instrument - The Non-Legally Binding Authoritative Statements of Principles for a Global Consensus on the Management, Conservation and Sustainable Development of all Types of Forests was produced in 1992 during the United Nations Conference on Environment and Development. The document which is considered to be juridically lamed was later amended to be known as the United Nations Forest Instruments ${ }^{3}$. In 2017, the Economic and Social Council adopted the United Nations Strategic Plan for Forests 2017-2030 and quadrennial programme of work of the United Nations Forum on Forests for the period 2017-20204. The Council recommended the adoption of this resolution to the General Assembly prior to the twelfth session of the United Nations Forum on Forests. The Strategic Plan is a global framework for action at all levels to sustainably manage all types of forests and trees outside forests and to halt deforestation and forest degradation. It also provides a framework for forest related contributions to the implementation of the 2030 Agenda for Sustainable Development; the Paris Agreement adopted under the United Nations Framework Convention on Climate Change; the Convention on Biological Diversity; the United Nations Convention to Combat Desertification in Those Countries Experiencing Serious Drought and/or Desertification, particularly in Africa; the United Nations Forest Instruments and other International forest-related instruments.

The United Nations Forest Instrument provides countries with a framework for promoting sustainable forest management. The key elements as defined in the instrument are:

(a) To strengthen political commitment and action at all levels to implement effectively sustainable management of all types of forests and to achieve the shared global objectives on forests

(b) To enhance the contribution of forests to the internationally agreed development goals, including the sustainable development goals, in particular with respect to poverty eradication and environmental sustainability

(c) To provide framework for national action and international cooperation.

Member States of the United Nations are enjoined to respect the principles built upon the Rio Declaration on Environment and Development which are:

\footnotetext{
. See the Preamble to the 1992 No n-Legally Binding Authoritative Statement of Principles for a Global Consensus on the Management, Conservation and Sustainable Development of all Types of Forests

2 . Principle 4 of the 1992 Non-Legally Binding Authoritative Statements of Principles

. The United Nations Resolution 70/199 adopted by the General Assembly on $22^{\text {nd }}$ December, 2015.

Resolution E/RES/ 2017/4
} 
(a) The Instrument is voluntary and non-legally binding

(b) Each State is responsible for the sustainable management of its forests and for the enforcement of its forest-related laws;

(c) Major groups as identified in Agenda 21, local communities, forest owners and other relevant stakeholders contribute to achieving sustainable forest management and should be involved in a transparent and participatory way in forest decision -making processes that affect them as well as in implementing sustainable forest management in accordance with national legislation

(d) Achieving sustainable forest-management in particular in developing countries as well as in countries with economies in transition, depends on significantly increased new and additional financial resources from all sources;

(e) Achieving sustainable forest management also depends on good governance at all levels;

(f) International cooperation including financial support, technology transfer, capacity building and education, plays a crucial catalytic role in supporting the efforts of all countries, particularly developing countries as well as countries with economies in transition, to achieve sustainable forest management.

The Instrument provides for four global objectives and they are:

(a) Reverse the loss of forest cover worldwide through sustainable forest management, including protection, restoration, and reforestation, and increase efforts to prevent forest degradation;

(b) Enhance forest-based economic, social and environmental benefits including by improving the livelihood of forest dependent people

(c) Increase significantly the area of protected forests worldwide and other areas of sustainably managed forests as well as the proportion of forest products from sustainably managed forests;

(d) Reverse the decline in official development assistance for sustainable forest management and mobilise significantly increased new and additional financial resources for the implementation of sustainable forest management.

In October, 2000, the Economic and Social Council of the United Nations established the United Nations Forum on Forests (UNFF), a subsidiary body with the objective of promoting management, conservation and sustainable development of all types of forests and to strengthen long term political commitments to this end. The forum is composed of all member states of the United Nations and specialised agencies. The instrument which was adopted in 2007 by the forum was endorsed by the General Assembly in 2015. It was the first time member states agreed to an international instrument for sustainable forest management. The opposition at the 1992 United Nations Conference on Environment and Development to a global forest treaty paved the way for the non-legally binding instrument. The United Nations Forest Instrument incorporates and has continued to recognise the International law principle to wit, "States have in accordance with the Charter of the United Nations and the Principle of international law, the sovereign right to exploit their own resources pursuant to their own environmental policy and have the responsibility to ensure that activities within their jurisdiction or control do not cause damage to the environment of other States or of areas beyond the limits of national jurisdiction". Also, there is the provision that States have sovereign and inalienable rights to utilize, manage and develop their forests in accordance with the development needs and level of socio-economic development and on the basis of national policies consistent with sustainable development and legislation, including the conversion of such areas for other uses within the overall socio-economic development plan and based on rational land -use policies. The fact that the United Nations Forest Instrument is not legally binding makes it imperative to depend on forest related treaties. The Forest Instrument is a document of principles for which no sanction is attached when the principles are derogated from.

\subsection{The United Nations Framework Convention on Climate Change-}

The treaty was adopted on 9 May, 1992 and it entered into force on 21 March, 1994. The objective is to stabilise greenhouse gas concentration in the atmosphere at a level that would prevent dangerous anthropogenic interference with the climate system. It recognizes the important role that forests play in climate change mitigation, as they represent a significant global carbon stock. The Intergovernmental processes of the United Nations Framework Convention on Climate Change(UNFCCC) and the Conference of the parties to the Kyoto protocol require parties to report and account for their greenhouse gas emissions from land-use activities such as forest management, cropland management, grazing land management and vegetation. Also, under the first commitment period of the Kyoto protocol, reforestation and afforestation projects located in developing countries are eligible for crediting under the Clean Development Mechanism ${ }^{1}$. The objective of the mechanism is to assist developing country parties to achieve sustainable development and to contribute to the ultimate objective of the UNFCCC and to assist developed country parties to achieve sustainable development and to contribute to the ultimate objective of the UNFCCC and to assist developed country parties to achieve compliance with the emission reduction commitments.

Nigeria is a party to the United Nations Convention on Climate Change and has also ratified the Kyoto Protocol. The objective of the Kyoto Protocol and the Framework Convention is to reduce greenhouse gas emission.

\footnotetext{
${ }^{1}$. The Rio Convention Action on Forests. https://unfccc.int. < accessed 16/7/19>
} 
Nigeria approved the National Policy on Climate Change and Response Strategy (NPCCRS), a national document for implementing climate activities in the country. The approval is to provide the government with a framework for tackling environmental challenges occasioned by global changes in the climate ${ }^{1}$. The adoption of the policy will enhance Nigeria's obligation towards reduction of the emission of obnoxious substances in the environment. The sources of the emission of the greenhouse gas in Nigeria includes gas flaring, bush burning, burning of fossil fuels by automobiles and industrial machines. The essence of the protocol is to commit developed countries that are mostly industrialised and are at the forefront of production and emission of gases which are harmful to the environment and which are responsible for climate change. The Doha amendment is to assist countries like Nigeria that are not producing any significant emission but suffering the consequences of greenhouse gas emission .The ratification will enable Nigeria and other developing countries stand to gain a lot in form of financial assistance and access to technology ${ }^{2}$. Nigeria has the highest rate of deforestation in the world according to the Food and Agricultural Organisations of the United Nations. Between 2000 and 2005, the country lost 55.7\% of forest land. Deforestation in Nigeria arises from logging, bush burning, subsistence and commercial agriculture, tree felling for charcoal or for fuel energy, uprooting of palm trees for palm wine. The human- induced deforestation can be reduced with good governance and this will enhance rapid socio-economic development. The government must evolve policy that will address poverty since most of the human activities are dictated by the force of poverty.

4.3 The 1992 UN Convention on Biological Diversity- the Convention is an international treaty for the conservation and sustainable use of biodiversity and the fair and equitable sharing of benefits arising out of the utilisation of genetic resources. Forests are biological diverse systems representing the richest biological areas on earth. Forests diversity is increasingly threatened as a result of deforestation, fragmentation, climate change and other harmful anthropological factors. The Convention on Biological Diversity addresses forest issues directly through its expanded programme of work on forest biological diversity, with the ecosystem approach as the primary framework for action, and through its other thematic programmes of work on cross-cutting issues.

Tropical, temperate and boreal forests offer diverse habitats for plants, animals and microorganisms, holding a large percentage of the world's terrestrial species. Forests biological diversity provides a wide array of goods and services, from timbre and non-timbre forest resources to playing an important role in putrefying, recycling and storing water and mitigating climate change. At the same time, it provides livelihoods and jobs for hundreds of millions of people worldwide ${ }^{3}$. The conservation of forests worldwide is basic to the protection of biodiversity which humanities depend for survival. This truth informed the decision of an ad hoc Technical Expert Group in 2002 at the sixth Conference of the Parties to the Convention on Biological Diversity to design the expanded programme of work on forest biological diversity. The programme consists of three elements. The first covers largely biophysical aspects such as the reduction of threats to forest biological diversity through restoration, agroforestry, and watershed management and the establishment of protected areas. The second element deals with institutional and socio-economic environment that in turn enables the conservation and sustainable use of forest biological diversity. The third aspect covers assessment and monitoring.

The earth conference of the parties to the Convention also adopted the strategic plan for Biodiversity 20112020 to promote the effective implementation of the Convention in order to halt the loss of biodiversity and ensure that by 2020 ecosystems are resilient and continue to provide services for human well-being and livelihoods. The strategic plan consists of 20 targets otherwise known as Aichi targets, some of which are relevant to the forests. Target 5 examines the rate of loss of all natural habitats, including forests. The rate of loss is to be reduced by fifty percent or to zero while degradation is to be significantly reduced ${ }^{4}$. Under target 7 , all areas under forestry managed are to be managed sustainably, ensuring conservation of biodiversity. Target 14 provides that ecosystem that provides essential services, including services related to water and contribute to health, livelihoods and wellbeing, are restored and safeguarded.

Conservation of biodiversity depends primarily on the protection of forest lands. The Expanded Programme of Work on Forest Biodiversity, a programme of action by the Secretariat of the Convention on Biological Diversity pointed out key areas in which government, international and regional organisations are to pay special attention. Some of the areas which are relevant for the protection of forests in Nigeria include the need to facilitate adequate participation of indigenous and local communities and the need to respect their rights and interests. In Nigeria, the indigenous people are familiar with the terrain and the geographical landscape of the forests. These people are indispensable in matters that relate to the protection of the forest and resources. Also, there is the need for urgent conservation action for forests that are ecologically significant and /or most important for biological diversity on national and regional scales, in accordance with national priorities, where forest biodiversity loss or threats of loss are significant or of great concern, but also to work to enhance conservation in all types of forests both within and

\footnotetext{
${ }^{1}$.International Centre for Energy, Environment and Development. https://iceednigeria.org/ic/ <accessed 16/7/19>

2 .https://www.environewsnigeria.com < accessed 31/08/19>

"Expanded Programme of Work on Forest Biological Diversity", Secretariat of the Convention on Biological https://www.cbd.int $>$ doc $<$ accessed 16/7/19>

4 . See the Rio Convention Action on Forests.
} 
outside protected areas. In Nigeria, wildlife hunting is taken as a profession by local hunters and this practice has resulted in extinction of some wildlife while some that are endangered are forced to migrate to other environment. Wildlife is endangered by the unsustainable practice of hunting and setting the forest ablaze in order to trap animals. It is pertinent to point out that apart from protected areas, poaching for wildlife and economic trees are carried out with impunity in Nigeria. Governments are to draw inspiration from the expanded programme of the Convention for Biological Diversity to protect the forest and the ecosystem. The expanded programme has the following goals:

(a)To apply the ecosystem approach to the management of forests

(b) To reduce the threats and mitigate the impacts of threatening processes on forests biological diversity

(c) Restore forest biological diversity in degraded secondary forests and forests established on former forest lands and other landscapes, including in plantations

(d) Promote sustainable use of forest resources to enhance the conservation of forest biological diversity

4.4 The World Charter for Nature- The Charter, though not legally binding consists of guiding principles of conservation to prevent human conducts inimical to nature. The principles, if strictly adhered to will prevent the wastage of natural resources. The Charter ${ }^{1}$ provides that, Natural resources shall not be wasted, but used with a restraint appropriate to the principles set forth in the present Charter, in

(a) Living resources shall not be utilised in excess of their natural capacity for regeneration;

(b) the productivity of soils shall be maintained or enhanced through measures which safeguard their long term fertility and the process of organic decomposition, and prevent erosion and all other forms of degradation;

(c) Resources including water which are consumed as they are used shall be exploited with restraint

Also significant in the Charter is the need to control activities that might have impact on nature. The discharge of pollutants into natural systems is also to be avoided ${ }^{2}$.

4.5 The 1994 UN Convention to Combat Desertification in Those Countries Experiencing Serious Drought and /or Desertification Particularly in Africa- The Convention recognises the importance of forests in combating the problem of desertification. One of the programmes of action recommended by the Convention is the afforestation and tree planting activities by individuals, organisations and governments ${ }^{3}$. Protection and expansion of forests are important elements of the Convention since forests have significant ecological functions that mitigate effects of drought and prevent desertification. Strategies to deal with desertification are likely to mitigate forest loss as well. Sustainable forest management is an important part of the corrective actions envisaged under the Convention to tackle land degradation, promote sustainable agricultural and rural development ${ }^{4}$.

4.6 Ramsar Convention on Wetlands of International Importance Especially Known as Waterfowl HabitatForests form the water catchment for many important wetlands, and many kinds of forests are wetlands too ${ }^{5}$. The significance of forest is no doubt the rational why the United Nations in 2011 chose as a team for the World Wetland's Day of the International Year of the Forests, the theme "Forests for Water and Wetlands". Wetlands include some of the most carbon -dense ecosystems in our planet, such as salt marshes, sea grass beds and mangroves. Wetlands are a vital source of foods, raw materials, genetic resources for medicines, and hydropower and they play an important role in transport, tourism and the cultural and spiritual well-being of people ${ }^{6}$. Wetlands are defined as all areas that are permanently inundated with a depth of water of maximum six metres.

4.7 Convention on International Trade in Endangered Species of Wild Fauna and Flora(CITES)- The Convention is primarily to prevent the extinction of endangered species of wild fauna and flora. The protection of the wild fauna for the present and future generations invariably demands the protection of the forests which is their habitat. Regulating the trade in these endangered species will ensure that they are not harvested indiscriminately since they will be subjected to special control. The exportation of the species is to be with the grant of permit issued by the management authority in the State. It is also to be noted that the management authority of the state can only grant permit for export where it is satisfied that the living specimen was not obtained in contravention of the laws of that State for the protection of fauna and flora ${ }^{7}$ The implication of this for the forest is that the trade restriction will reduce the urge for poaching of wildlife and for the protection of the forests

4.8 Convention for the Protection of the World Cultural and Natural Heritage- The Convention was adopted on the $16^{\text {th }}$ day of November 1972 by the general conference of UNESCO. Natural heritage according to the Convention includes natural features, geological and physiographical formations and natural sites. Geological and physiographical formations mean delineated areas which constitute the habitat of threatened species of animals and plants of outstanding universal value from the point of view of science or conservation. Natural sites mean delineated natural areas of outstanding universal value from the point of view of science, conservation or natural

\footnotetext{
${ }^{1}$.Paragraph 10 of the Charter

2 .See paragraph 12 of the Charter

3 .Article 2(1) of the Convention

${ }^{4}$ Global Conventions Related to Forests- unasylva 206. www.fao.org/3/y1237e/y1237e03.htm <accessed 16/7/19>

5 ." Forest for Water and Wetlands"-Birdlife international. https://www.birdlife.org <accessed16/7/19>

6 .'Wetlands Disappearing Three Times Faster than Forests". UN Climate Change News, 01 October, 2018. https://unfccc.int/news <accessed $19 / 7 / 19>$

7.Article 4(2)(b) of the Convention
} 
beauty ${ }^{1}$. The relevance of the Convention which came into force in 1975 to forests is that some of the natural heritage sites are in the category of tropical forests. The Convention is a Conservation instrument and the policy thrust is that some natural sites are so important that their protection is not only the responsibility of a single nation but also the duty of the international community as a whole.

4.9 The Vienna Convention for the Protection of the Ozone Layer-The Convention is the first international agreement dedicated to the protection of the Ozone layer. In 1987, the Montreal Protocol on Substances that Deplete the Ozone Layer was negotiated as a protocol to the Vienna Convention. The relevance of the Ozone regime for forests is the link between depletion of ozone layer and these possible adverse effects this might have on forests.

4.10 The 1989 Indigenous and Tribal Peoples Convention-The Convention is an International Labour Organisation (ILO) instrument also known as ILO Convention 169. It is the major binding international Convention concerning indigenous people and tribal people. The Convention which came into force on 5 September, 1991 has continued to play a key role in saving the world's rainforests, putting control of the land back in the hands of the people who have looked after it for generations ${ }^{2}$.ILO 169 recognises and protects tribal people's land rights allowing tribes to prosper and the forests in which many live to flourish. The only African country that has ratified this Convention is the Central Africa Republic. The Convention provides that the rights of ownership of the peoples concerned over the lands which they traditionally occupied shall be recognized. In addition, measures shall be taken in appropriate cases to safeguard the right of the peoples concerned to use the lands not exclusively occupied by them but to which they have traditionally had access for their subsistence and traditional activities ${ }^{3}$ The Convention provides further that the right of the people concerned to the natural resources pertaining to their lands shall be specially safeguarded. These rights include the right of the people to participate in the use, management and conservation of these resources.

Nigeria Statues Relevant to the Conservation of Forests

4.11 Forestry Act No. 31 of 2014- The goals of the Act are to make further and better provisions in relation to forestry; to provide for the development and promotion of forestry in a manner that maximises the economic, environmental and social value of forests within the principle of sustainable forest management.

Forest under the Act means a land under trees with-

(a) a minimum area of 0.1 hectare, and

(b) tree crown cover of more than 20 per cent of the total area, or the potential to achieve this cover at maturity, and includes all special trees.

The Act recognises ownership of forest by individuals and such owner includes freehold owner, leasehold owner or the occupier for the time being of the lands concerned. The Act confers on the minister of Agriculture a wide range of general and specific functions for the protection of forest lands and resources. The general functions of the Minister ${ }^{4}$ centre around activities designed to protect the forests and promoting afforestation. The specific functions 5 include the granting of licences for the felling or otherwise removing of a tree and the thinning of a forest; afforestation; forest road works and aerial fertilisation of forests; acquisition or disposition of land suitable for afforestation or for any other forestry related activities. The Act empowers the Minister to require the owner of a forest to submit a forest management $\operatorname{plan}^{6}$. An owner of a forest has a duty to notify the minister where a forest is destroyed or removed in whole or in part otherwise than in accordance with the Act, by any means (including fire or natural causes) and the Minister may subsequently serve a replanting order ${ }^{7}$. The Minister is empowered to exercise precautionary measures for the protection of forest lands. This will happen where a minister is satisfied that trees in a forest are at significant risk of being damaged by fire originating from an uncultivated land in the vicinity of the forest by reason of the presence thereon of vegetation. The Minister may serve on the owner of the land concerned a notice in writing stating that the vegetation constitutes a danger to those trees and directing that the vegetation be removed or destroyed ${ }^{8}$. Also where trees in a forest are under the threat of destruction by vermin in the land the vicinity of a forest, the Minister may give an order for the destruction of the vermin ${ }^{9}$.

Another proactive measure the minister can take to preserve the forest land is the exercise of the power to prohibit the felling or otherwise removing or the continued felling of trees from the forest $\mathrm{t}^{10}$. The Minister is also empowered to grant licence for afforestation, forest road works or aerial fertilization of forest ${ }^{11}$. Where tree have

\footnotetext{
1 .Article 2 of the Convention

.Survival 1169. The International Law for Tribal People. Survival international.org

Article 14

${ }^{4}$. Section 5 of the Act

5 .Section 6 of the Act

${ }^{6}$.Section 10 of the Act

Section 12 of the Act

Section 14 of the Act

Section 15 of the Act

. Section 20 of the Act

. Section 22 of the Act
} 
been felled or otherwise removed without a valid licence or felled under a licence, and either at the same time of such felling or subsequently, a condition of the licence is contravened, or in the opinion of the Minister, seriously damaged, the Minister may issue a replanting order in respect of the owner requiring him/her to replant ${ }^{1}$. The Act provides for offences and penalties for the contravention of the provisions of the $\mathrm{Act}^{2}$.

4.12 Endangered Species (Control of International Trade and Traffic) Act ${ }^{3}$ - The Act was amended in 2016 to review the fines upward. The Act provides for the conservation and management of wildlife and the protection of some endangered species of fauna and flora. The Act prohibits hunting or capture of or trade in animal species listed in the first schedule of the Act. On the animals listed in second schedule, the Act provides that no person shall hunt, capture, trade in or otherwise deal with an animal species specified except the person is in possession of a licence issued under the Act. The Act prohibits also the use of certain methods in capturing fish, take or hunt wild animals. These are methods that can cause mass destruction; the use of drugs, poisons, poisoned weapons or poisoned baits; the use of mechanically propelled vehicle for hunting; the use of fire; the use of firearms capable of firing more than one round at each pull; hunting or capture at night; or the use of missiles containing detonators ${ }^{4}$. 4.13 Bees (Import, Control and Management) Act, Cap B6 LFN, 2004- The Act was amended to take effect on the $18^{\text {th }}$ of November, 2016. The Act provides for the control of importation of bees and apicultural material and the spread of diseases and pests among bees. Importation into Nigeria of any bees or any apicultural material for use in connection with bees or bee keeping requires a permit of the minister of agriculture. The Act provides for the seizure, detention and destruction of bees or material illegally imported into the country.

4.14 National Agricultural Land Development Authority Act Cap N4 LFN, 2004- The goals of the Act is to create an agency that will enable the government provide strategic public support for land development; to promote and support optimum utilisation of Nigeria's rural land resources for accelerated production of food and fibre; encourage and support economic-size farm holdings and promote consolidation of scattered fragment holdings to generate net income from agriculture aimed at sustaining living standards above the poverty line and thereby narrow rural-urban income inequalities; encourage the evolution of economic size rural settlements that will reap the economies of scale in the provision of social infrastructure; provide gainful employment for rural people, raise rural incomes and improve on the general living standards in rural areas; expand productive capacity in agriculture and regain export capability in traditional and non-traditional crops; contribute significantly towards the attainment of a national food and fibre self-reliance, self-sufficiency and national food security; facilitate appropriate cost-effective mechanisation of agriculture ; and institute strategic land use planning schemes to deal with major allocation problems including the creation and location of forest and grazing reserves and other areas with explosion, pressure or national disaster.

4.15 National Environmental Standards and Regulations Enforcement Agency (Establishment) Act,2007The Act is the primary legal instrument for the protection and development of the environment in Nigeria. The main objective of the Act is the protection and development of the environment, biodiversity conservation and sustainable development of Nigeria's natural resources in general and environmental technology including coordination and liaison with relevant stakeholder within and outside Nigeria on matters of enforcement of environmental standards, regulations, rules, laws, policies and guidelines.

4.16 The Federal National Parks Cap N65 LFN, 2004- The Act is concerned with the establishment of protected areas used for resource conservation, water catchment protections, wildlife conservation and maintenance of the national ecosystem balance. There are eight national parks in Nigeria covering 20,156 square kilometres and they play a vital role in the conservation of Nigeria's wildlife. The National parks portray the success or failure of governmental policies as implemented and provide opportunities for improvement on conservation policies. The parks ensure that the natural ecosystems remain intact and shield them from negative external factors.

4.17 Forestry Law of Ekiti State of Nigeria ${ }^{5}$ - Agriculture is a matter on the concurrent list of the 1999 Constitution of the Federal Republic of Nigeria; hence both the Federal and the State governments are empowered to make laws on agriculture. The law prohibits certain activities among which are uprooting, burning and stripping off the bark or leaves of trees; setting fire on grass or garbage; smoking or lighting a fire in any part of a forest reserve; pasturing or trespassing by cattle; digging, cutting or cultivating the soil or making a farm or plantation; construction of dam or weir across any river or stream or obstruction of any river or stream ; residing or erecting any building within the forest area. These prohibited activities attract penalties ranging from fines to imprisonment or to both fine and imprisonments.

5.0 The Reality of Conservation and Management of Forests in Nigeria- There are enough legal provisions that can be invoked for the conservation and management of forest lands and resources in Nigeria, but the reality is that the legal provisions are like paper tiger and therefore honoured more in breach than in observance. Some of

\footnotetext{
Section 26 of the Act

Section 27 of the Act

Cap E9 Laws of the Federation of Nigeria, 2004

Section 5(6) of the Endangered Species (Control of International Trade and Traffic) Act

Cap F3 Laws of Ekiti State Of Nigeria, 2012
} 
the sanctions contained in the legal instruments are frail or impotent that they cannot deter a potential offender. The forests in Nigeria are like orphan without anybody showing concern as to their preservation. For instance all the prohibited activities contained in the Forestry Law of Ekiti are perpetrated to the knowledge of the government. The forests in Nigeria have become the abode of criminals such as herdsmen that engaged in kidnapping to complement their trade. They have cells in almost all the forests. The awareness of these nefarious activities of herdsmen prompted the governments in the southern parts of Nigeria to set up security networks to stem the tide of criminalities in the forests. Apart from herdsmen operating as kidnappers, there are narcotic drug farmers that engage in large scale commercial cultivation of marijuana (Indian hemp) in the forests. Illegal felling of economic trees and poaching for wild animals are frequent activities within the forest without any positive step to curb the prohibited acts. There are laws but the governments lack the political will to enforce the laws. The forest lands in Nigeria have abundant resources that can support the economic base of the state governments but because of heavy reliance on allocation of oil revenue, the state governments and even the federal government have closed their eyes to the need to conserve the forests. Adequate protection of forests requires the government to put in place manpower and equipment for effective monitoring of activities within the forests. The security of the forests required trained professionals known as Forest Guards. This category of personnel existed adequately up till about two decades ago, but today only few states with forests can boast of this category of personnel. In States where they exist, they are not sufficient and apart from adequate manpower, they exist without facilities and ammunitions to confront the criminals that have turned the forests into their habitation. As earlier mentioned in this paper, the only protected forests are the game reserves and national parks. The interests of the government in forests are more economic than that of sustainable development. Forestry offices are located far away from the forests; hence it is possible to carry out illegal felling and processing of same within the forest environment.. Timbre contractors in some cases obtain permit to fell trees but the Guards do not normally investigate the location where the trees have been harvested. Apart from this, it should be made a pre-condition before a licence or permit is granted for a timbre contractor intending to fell economic trees to give an undertaking of programmes for replanting. Timbre merchants should be mandated annually to participate in the annual tree planting programme of the government.

Legal instruments whether international or national have proved to be ineffective in the conservation of forest lands and resources in Nigeria. This paper is not advocating exclusively the use of traditional methods of designating the forests as prohibited lands, but such customary practices of designating forest land and resources untouchable will help to preserve the forests in Nigeria. Civilisation today has made many communities in Nigeria to destroy some ancient trees within the towns and urban centres. Some lands dedicated to the worship of ancestral gods have the tendency of maintaining their natural features as people will be scared of carrying out activities detrimental to the lands. For instance, in 2019, no fewer than thirty-six cattle were reportedly killed by thunderstorm at a sacred mountain in Ijare, Ifedore Local Government, Ondo State, Nigeria. The incident was described as the wrath of the gods against the herdsmen that had been warned severally not to trespass to the area which only the traditional ruler is allowed to visit once in a year for sacrifice ${ }^{1}$. In the South Eastern part of Nigeria, there are some rivers and streams where fishing is prohibited not by ordinance but by customs. There are also some villages where certain animals like snakes are worshipped and for that, they are preserved and cannot be killed by hunters or anybody. Effective conservation and management of the forest lands and resources demand that the customary practices should be incorporated into the laws while at the same time the native should be allowed to participate in the conservation of the forest lands. The existing laws should be updated while the government should arise and make the conservation of the forest lands and resources a priority.

\subsection{Conclusion-}

Conservation and management of forests in Nigeria demand serious attention in order to achieve the goals of sustainable development. Existing legal instruments require enforcement and the commitments of the government. Governments at both the States and federal level should evolve measures for the training of more professionals in forestry matters while at the same time, equipment for adequate surveillance should be procured to enable Guards perform their duty. The Forest Guards should be allowed to carry ammunitions for adequate security of their lives against any attacks by criminals or wild animals. Traditional rulers and local communities should be incorporated in the task of protecting the forest lands and resources through an enabling law. The government should also address urgently the problems of youth unemployment which has turned many of the youths to emergency timbre contractors. Government should also address the issue of poverty that has made people to depend on fire wood as source of fuel energy by social intervention of providing free-of-charge or subsidising the cost of cooking gas and kerosene stove to the indigent people in the rural communities. The situation of the forests in Nigeria has revealed that a lot has to be done by the government in order to arrest the ugly state of the forests.

\footnotetext{
1. "Thunder Allegedly kills 36 cows in Ondo Community", https://sahara reporters.com. 2019/09/22<accessed 4/11/19>
} 